\title{
Editorial
}

\section{Proteomics and Nutrition - A science for the first decade of the new Millennium}

\begin{abstract}
When I took on the role of Editor-in-Chief of the British Journal of Nutrition I determined that I would write no more than two editorials a year, one at the beginning of each volume. Two particular editorials are likely to be of special significance during my tenure - the first, which appeared in the July issue of last year outlining my priorities for the $B J N$, and the present one. I say the present one because it is the first of the new Millennium. Many, of course, will have grown weary of the constant emphasis on all things to do with the Millennium. This is partly because of the continual 'marketing' of the event, partly its rather arbitrary nature (based on the Judaeo-Christian calendar) and partly because of the view that it really begins in the year 2001 and not 2000. Notwithstanding these somewhat jaundiced perspectives, I should like to discuss a new area of science which is likely to be of key importance for the first decade of this Millennium, and which will I believe have a major impact on nutritional science; this is the area of proteomics.
\end{abstract}

The term 'proteomics' was first coined some five years ago (Wilkins et al. 1996) and its roots lie conceptually in genomics. The emphasis on the gene, with the human genome project directed at sequencing the entire human genome (with other initiatives targeted at the genome of other species), has led to the recognition that the information obtained has distinct limitations, as well as offering considerable opportunities. The central limitation is that the genome provides a blueprint and reflects the potential of an organism - but the genome itself does not tell us what actually takes place. Thus all cells contain the complete genome of a given organism, but not all genes are expressed within each cell type. Adipocytes, for example, do not express the gene encoding haemoglobin.

The proteome is defined as all the proteins that are present in a particular cell at a particular time (the PROTEin complement expressed by a gen $O M E$ ), reflecting the expression of specific genes in the situation pertaining at that point. The practical realisation of proteomics depends upon the ability to identify and analyse each of the protein products in a cell or tissue, and this is reliant on the application of several key technologies.

The first stage in proteomics is the extraction of proteins and their separation by two-dimensional (2-D) gel electrophoresis. The first dimension of such a separation uses isoelectric focusing, based on the isoelectric point of the protein, with an important technical advance in the form of the introduction of immobilised $\mathrm{pH}$ gradients embodying a wide $\mathrm{pH}$ range. The second dimension separates the proteins according to molecular weight, utilising sodium dodecyl sulphate- polyacrylamide gel electrophoresis. The separated proteins may be detected by several means, the least sensitive being staining with Coomassie Blue, with silver staining being more sensitive by 1-2 orders of magnitude. Greater sensitivity still is achieved by fluorescence detection following the labelling of proteins with fluorescent dyes.

Major developments in image analysis have enabled the complex protein patterns obtained to be mapped and analysed, there often being several thousand separate spots on a single 2-D gel. Mass spectrometry (MS) provides the customary means by which individual proteins can be identified following proteolytic digestion in situ within a gel spot by enzymes such as trypsin. The precise molecular mass which can be obtained by MALDI (matrix-assisted laser desorption ionisation) MS of the peptides obtained from proteolytic digestion often allows the identification of a protein by reference to databases. In some cases, partial sequence analysis, such as for the $\mathrm{N}$-terminal region, is required for definitive identification. In many cases, however, a given protein will not be in the databases and will represent a novel molecular species. Such a protein will need to be cloned and its function determined.

Proteomics can be used to identify the entire protein complement of a cell, tissue, or micro-organism at different stages of development, and to examine the integrated response to a particular challenge. The challenge may be hormonal, environmental, or nutritional (in whatever form). As well as revealing the presence of novel proteins, a major application of proteomics is in trying to identify at a protein level early changes involved in degenerative and other diseases, such as in the pancreatic $\beta$-cell in diabetes (Andersen et al. 1997). This may be valuable either to provide insight into the causes of a disease, or in identifying an early marker of the initiation of the disease process (Andersen et al. 1997; Byrjalsen et al. 1999). For the nutritional scientist this is clearly of special interest in relation to those diseases where diet plays an important role.

The major pharmaceutical companies have geared up rapidly to harness proteomics in the search for novel drug targets, and more and more academic centres are actively involved in the field. There is no doubt, therefore, that proteomics will be a key area of biology during the first decade or two of the new Millennium, and that it will have major impact, both directly and indirectly, on nutritional science. I hope and expect that it will not be long before the $B J N$ receives and publishes its first paper on the application of proteomics to our particular specialism.

Paul Trayhurn

Editor-in-Chief

British Journal of Nutrition 


\section{References}

Andersen HU, Fey SJ, Larsen PM, Nawrocki A, Hejnaes KR, Mandrup-Poulsen T \& Nerup J (1997) Interleukin-1 beta induced changes in the protein expression of rat islets: A computerised database. Electrophoresis 18, 2091-2103.

Byrjalsen I, Larsen PM, Fey SJ, Nilas L, Larsen MR \& Christiansen C (1999) Two-dimensional gel analysis of human endometrial proteins: characterisation of proteins with increased expression in hyperplasia and adenocarcinoma. Molecular Human Reproduction 5, 748-756.

Wilkins MR, Sanchez JC, Gooley AA, Appel RD, HumpherySmith I, Hochstrasser DF \& Williams KL (1996) Progress with proteome projects: Why all proteins expressed by a genome should be identified and how to do it. Biotechnology and Genetic Engineering Reviews 13, 19-50. 